\section{ANEXO \\ FIBRAS DE LINO EN LAS \\ PILETAS DEL POBLADO IBÉRICO DEL COLL DEL MORO (GANDESA, TERRA ALTA): ESTUDIO PALEOETNOBOTÁNICO}

\author{
FLAX FIBRES IN WATER-BASSINS \\ FROM THE IBERIAN SETTLEMENT OF \\ THE COLL DEL MORO (GANDESA, \\ TERRA ALTA, SPAIN): \\ A PALEOETHNOBOTANICAL STUDY
}

\section{NATÀLIA ALONSO I MARTÍNEZ (*) JORDI JUAN I TRESSERRAS (**)}

\section{RESUMEN}

En el presente estudio presentamos los resultados obtenidos en las investigaciones realizadas sobre la funcionalidad de las piletas del poblado ibérico del Coll del Moro (Gandesa), en las cuales detectamos una importante presencia de fibras de lino.

\begin{abstract}
In this paper we offer the results of research on flax fibres discovered in water-bassins of the Iberian settlement of Coll del Moro (Gandesa, Spain).
\end{abstract}

Palabras clave: Arqueobotánica, Fibras vegetales, Fitolitos. Lino. Microscopio Electrónico de Barrido.

(*) Becaria F.P.I. del M.E.C. Secció d'Arqueologia, Prehistoria i Historia Antiga. Universitat de Lleida. Bisbe Messeguer, s/n. 25003 Lleida.

$\left.{ }^{* *}\right)$ Seminari d'Estudis i Recerques Prehistoriques. Departament de Prehistòria, Historia Antiga i Arqueologia. Universitat de Barcelona. Baldiri i Reixac, $\mathbf{s} / \mathbf{n}$. Torre B pis 11. 08028 Barcelona.

El artículo fue remitido en su versión final el 10-VI-94.
Key words: Archaeobotany. Vegetal fibres. Phytoliths. Flax. Scanning Electron Microscope.

\section{INTRODUCCIÓN}

En la base de dos piletas localizadas en el poblado del Coll del Moro se detectó un sedimento de coloración gris-negruzca que presentaba abundantes restos vegetales (UE 314 y UE 341) y que fue muestreado para su estudio posterior.

Tras la extracción de la muestra del contenedor estéril, por la gran abundancia de materia orgánica, se procedió a su eliminación mediante un tratamiento con Peróxido de Hidrógeno (33\%). A continuación se procedió a realizar la separación de las diferentes fracciones. En particular nos centramos en las fracciones de arenas finas $(250-50 \mu \mathrm{m})$ y limos $(50-2 \mu \mathrm{m})$ dado que son las que presentan una mayor concentración de microrrestos vegetales.

Se cribaron 50 gr. de sedimento, con agua destilada, en una columna de dos cedazos de 250 $\mu \mathrm{m}$. Las arenas finas se reservaron para su análisis, mientras que los limos resultantes del cedazo de $50 \mu \mathrm{m}$, en una suspensión con hexame- 
tafosfato sódico. se fraccionaron a continuación por sedimentación. según la Ley de Stockes: en tres tamaños 5()-20 $\mu \mathrm{m}$. 2()-8 $\mu \mathrm{m}$ y $8-2 \mu \mathrm{m}$. Este sistema, básico en la mineralogia, ha demostrado ser muy útil en el estudio de fitolitos en sedimentos arqueológicos, ya que se agrupan las fracciones mencionadas, facilitando el contaje. la distribución en diferentes morfologías y la identificación (García-Calderón et alii, 1993).

Las fracciones obtenidas se estudiaron por microscopía electrónica de barrido (SEM), utilizando un modelo (ambridge Stereoscan s-120. con microanálisis (EDS) Link incorporado. aplicando las técnicas desarrolladas para el estudio de fibras (Körber-Grohne, 1988) y microrrestos vegetales (Juan, 1993) procedentes de yacimientos arqueológicos.

En las fracciones de arenas finas $(200-50 \mu \mathrm{m})$ y limo $(50-2 \mu \mathrm{m})$ se concentraron especialmente restos de fibras, estructuras multicelulares y fitolitos (células alargadas, fragmentos de epidermis, estomas....) que respondían a las características del lino (Linum usitatissimum L.). Se detectaron también algunas fibras que parecen corresponder a cáñamo (Cannabis sativa $\mathrm{L}$.).

Las fibras del floema del lino, clasificadas como blandas desde un punto de vista comercial, son fibras extraxilares que se componen de celulosa prácticamente pura con una tolerancia de 2 a $4 \%$ de lignina que se elimina en el blanqueo (Esau, 1985). Las fibras se hallan en grupos o haces con diámetros que alcanzan medio milímetro, consistiendo cada uno de ellos en un número de células de fibra de un diámetro de $1 / 100$ de $\mathrm{mm}$. El haz, en conjunto, parece como una fibra de 30 a $90 \mathrm{~cm}$. de longitud después de agramada (Schery, 1956).

El análisis antracológico realizado por Jaume Enric Zamora (comunicación personal) en las mismas unidades se ha visto dificultado por el proceso de mineralización que han sufrido los fragmentos de carbón vegetal. Este estado distorsiona su estructura anatómica original provocando que su identificación no sea posible de una forma clara y precisa. A pesar de ello, podría tratarse de lentisco (Pistacia lentiscus $\mathbf{L}$.) o de alguna leguminosa.

\section{EL LINO (Linum usitatissimum L.)}

El lino es una planta herbácea anual perteneciente a la familia de las Linaceae, de tallo- delgado, ramificado. de 0.50 a $1 \mathrm{~m}$. de altura: hojas planas. lineales. enteras. las superiores más estrechas; flores en cimas terminales, grandes, de unos $2 \mathrm{~cm}$., de pétalos azules o blancos y semillas aplanadas en cápsulas .

Existen dos tipos de linos cultivados: el lino de invierno o frío y el lino de verano o caliente (Serra, 1879; Remussi, 1956). El lino de invierno se cultiva en España y en otros países mediterráneos, y tiene la ventaja de adaptarse con facilidad a cualquier suelo, sea cual fuere su fertilidad, factor que lo diferencia de las variedades sembradas en primavera. Sus tallos son más gruesos, más altos y ramificados, produciendo cápsulas de mayor volumen, siendo también más productivo que el lino de verano, pero su hilaza es más áspera y ordinaria .

Existen variedades de lino para fibra (textiles) y para semilla (oleaginosos). En el caso que nos ocupa nos centraremos específicamente en el aprovechamiento del lino con finalidad textil, variedad más delicada que precisa una ausencia de heladas durante la germinación, lluvias poco intensas y repartidas, así como temperaturas frescas durante el proceso de crecimiento, y más cálidas y secas durante la fructificación y cosecha. Los lugares más apropiados para el cultivo del lino son los situados cerca del mar, que atenúa las variaciones bruscas de clima. Un ambiente seco, con cielo siempre despejado y las alternativas de calor y frío, dan fibras cortas, bastas y quebradizas.

Los suelos de mediana fertilidad con un buen drenaje son los apropiados para su cultivo. Aparte de las condiciones propias del suelo es muy importante que en el mismo no haya una excesiva cantidad de semillas de malas hierbas, ya que el lino se defiende muy mal de esta vegetación espontánea.

Antes de la siembra se tiene que arar profundamente ya que la semilla de lino es de pequeño tamaño, delicada y necesita un terreno muy bien preparado. Las variedades de invierno se siembran generalmente en Septiembre u Octubre y las de verano en Marzo o Abril. Plinio (H.N., XIX, 2, 1) habla de siembra de primavera, con cosecha en otoño, mientras que Columela (De re rust. II, 10, 17) lo hace de siembra en otoño: desde las Calendas de Octubre hasta siete días antes de los Idus de Diciembre. Es necesario sembrar en forma densa ya que de este modo los tallos resultan altos, finos y poco o nada ramificados. Las variedades olea- 
ginosas. en cambio, precisan de espacio para poder ramificarse y dar una gran producción de semillas. Columela propone una siembra lo más espesa posible (De re rust. II, 10, 17). Los autores difieren respecto a la forma de siembra, a volea (Miró, 1908: 74) o en línea (Remussi. 1956: 29: Liró, 1968: 183)

Posterior a la siembra, la única labor que necesita el lino es el desmalezado. En el lino textil las malas hierbas son más perjudiciales que en el oleaginoso, ya que entorpecen los procesos a que se somete la paja para la obtención de la fibra. Esta variedad también se diferencia de la de grano en su cosecha que se efectúa unos 20 ó 30 días antes. La cosecha se realizaba en diferentes épocas según el uso que se iba a dar a la fibras: todavía verde, daba fibras bastante flexibles para tejidos muy finos; amarillo daba fibras más resistentes; y completamente maduro, se adaptaba mejor a los trabajos de cuerdas y cestas (Leospo, Pedrini \& Chiostaso, 1989: 76; Amouretti, en prensa). Si se espera a que las semillas estén maduras la paja se pasa de punto volviéndose quebradiza y de fibra áspera. De todas maneras la semilla completa su estado durante el secado de la paja.

El rendimiento y la calidad de la fibra a obtener depende de cómo se realice la cosecha. Las plantas no se cortan, sino que se arrancan para aprovechar todo el largo del tallo. Los tallos se colocan en gavillas o haces y se amontonan en grupos de 3 ó 4 para que terminen de secarse, uno o dos días después de efectuarse el arrancado.

Columela (De re rust. II, 12,5) calcula el coste de tiempo que lleva el cultivo del lino: "Ocho o diez modios de lino se siembran con cuatro días de labor, se gradan en tres jornadas, se deshierban en una, se arrancan en tres, total: once jornadas".

\section{EL PROCESO DE PRODUCCIÓN DE LA FIBRA DE LINO}

La fibra de lino es la más difícil de preparar para tejer. Se consigue a partir de una serie de procesos: el desbolillado o desemillado, el enriado, el secado de la paja, el agramado y el desfibrado. Las principales operaciones de preparación del lino, así como los útiles empleados, han llegado a nosotros casi sin cambio. Pinturas egipcias del Imperio Antiguo nos muestran un orden casi análogo, $y$ aunque las pruebas materiales sean pocas se puede suponer una sucesión igual de operaciones en la prehistoria europea (Clark. 1955: 346: Leospo. Pedrini \& Chiostaso, 1989). (omentaremos brevemente cada una de estas operaciones.

Desbolillado: tiene por objeto separar las semillas de los tallos. Se realiza con un peine. generalmente fijo, en el que se introducían los manojos por la parte superior y se tiraba. Al ser el diámetro de las cápsulas mayor a la distancia existente entre los dientes, éstas quedaban separadas de los tallos.

Enriado: es un proceso de fermentación en el que, por medio de microorganismos que traen consigo las mismas plantas, se produce la disolución del cemento péctico que une entre sí las fibras, transformándose en ácido péctico. Este proceso es el más interesante para nosotros, ya que podría considerarse como uno de los usos de las estructuras conservadas en el poblado del Coll del Moro. Existen diversos tipos de enriado: naturales (en agua corriente, agua estancada $o$ al rocío) $o$ artificiales (en agua caliente o por medios físico-químicos). El que más se acerca a nuestras estructuras sería el enriado en agua estancada, en concreto el llamado enriado en piletas. En este tipo de enriado las gavillas de lino se depositan en el interior de la pileta, ya sea vertical u horizontalmente, y se cubren con agua, seguidamente se colocan unos pesos encima (piedras o troncos) para que queden bien sumergidas. Generalmente las piletas son de forma rectangular y con una profundidad no superior a $1,50 \mathrm{~m}$. (en el caso de que el lino se coloque en posición vertical). A partir de aquí vendrán tres fermentaciones sucesivas:

- una fermentación insensible en la que el agua penetra en los tallos haciendo salir el aire, con las consecuentes burbujas, y en la que el agua va tomando un color pardo-negruzgo;

- una fermentación acética (que produce ácido carbónico), a las ocho o diez horas cuando empiezan a desarrollarse los microorganismos;

- finalmente una fermentación pútrida (produce hidrógeno carbonatado), las bacterias atacan las partes fácilmente descomponibles, el agua cambia de olor, 
volviéndose desagradable y las fibras se separan finalmente.

La duración del enriado varía según la temperatura que tenga el agua, de 3 ó 4 días (a $30^{\circ}$. $32^{\circ}$ ) hasta 1 mes en invierno. Debido a los gases que desprenden los tallos enriados, este procedimiento es muy antihigiénico, dando lugar en más de una ocasión a diferentes enfermedades y pestes.

Es sorprendente los pocos testimonios arqueológicos que se han encontrado de este proceso, posiblemente debido a que los métodos más utilizados podian ser el del enriado al rocio o el de en agua corriente. En un yacimiento medieval suizo (Charaviene-Colletière) se detectó el enriado de cáñamo gracias a unas concentraciones de polen de esta planta, en la ribera de un lago (Mille, Colardelle \& Verdel, 1989: 251). El enriado de lino en Tarragona comentado por Plinio (H.N., XIX, 2,4) era también del tipo en agua corriente.

Secado de la paja: una vez finalizado el enriado se vacía la pileta y se sacan las gavillas, llevándolas a un espacio abierto para que se sequen.

Agramado: consiste en la fragmentación en pequeños trozos de la parte leñosa de los tallos (agramiza), para el mismo tiempo aflojarlos. Esta operación se llevaba a cabo a base de golpes, ejecutados con una maza, hasta que en el siglo XIV fue substituida por la agramadera.

Desfibrado: consiste en separar los trozos de leño y efectuar un primer peinado de la fibra.

La hilaza es el conjunto de fibras largas resultantes del agramado que posteriormente pasan al proceso del peinado a fin de paralelizar las fibras y eliminar los elementos que no le confieren buena calidad (productos leñosos, malas hierbas, fibras cortas, restos de estopa). El rendimiento del lino, según Plinio (H.N., XIX, 18 ) es de un $20 \%$ aproximadamente: 15 libras de lino peinado por 50 libras de haces. Este resultado puede parecer mínimo pero se compensa por el rendimiento de los otros productos que se obtienen. Las fibras más cortas, los fragmentos y la estopa, separados durante la operación de agramado, son recuperados y utilizados para hacer telas bastas y cuerdas; la estopa se utilizó como combustible. Por otro lado, las semillas maduran a pesar de que la planta haya sido cortada y pueden ser aprovechadas (León-Garré. 1964).

\section{CONCLUSIONES}

La preservación de los restos de tallos y las fibras de lino en los depósitos del Coll del Moro (Gandesa) responde a condiciones similares de conservación de materiales orgánicos en un medio húmedo y carente de aire (anaerobio) producidas en lagos. pantanos... si un yacimiento húmedo se seca incluso sólo de forma estacional se puede producir la descomposición de los materiales orgánicos (Renfrew \& Bahn, 1993: 61).

Las características del proceso del enriado del lino en piletas, en el que se produce un estadio inicial en el que actúan las bacterias aerobias que luego ceden su lugar a las anaerobias que consumen el oxígeno del agua, conllevan a determinar que en el momento de destrucción de este establecimiento industrial, se dieran estas condiciones especiales que han permitido la conservación de las fibras, restos de tallos e incluso fragmentos de madera mineralizada. Por otro lado, la presencia de carbonato cálcico en unos de los depósitos, puede ser un indicativo de este proceso, ya que es utilizado para neutralizar los ácidos que se generan durante la descomposición (Lazarkévitch, 1925).

Los paralelos más cercanos los tendríamos en los yacimientos lacustres suizos en los que el proceso de fermentación ha permitido conservar tallos, cápsulas, semillas, fibras y restos de tejidos (Geijer, 1979: 266; Remussi, 1956). Por otro lado, un caso similar sería la tumba de un jefe celta de Hochdorf (Alemania), cronológicamente situada entorno al $550 \mathrm{AD}$ en la que los análisis por SEM descubrieron que el lecho mortuorio había estado cubierto por tejidos con urdimbres hiladas y retorcidas de cáñamo y lino (Körber-Grohne, 1988: 73-82).

El lino en la zona de Gandesa es un cultivo tradicional que, junto al cáñamo, no sólo formaba parte de las especies básicas para la subsistencia, sino que representaba una de las especies que ha caracterizado una industria artesanal en las comarca catalanas del Valle del Ebro, el Matarraña, el Bajo Aragón y el norte de Castellón.

En el caso del cultivo del lino en el poblado ibérico del Coll del Moro, éste podría tener una doble finalidad: el uso de las fibras, como las 
documentadas en los depósitos anteriormente citados, y la extracción de aceite de sus semillas.

En este sentido, en el NE. de la Peninsula Ibrica, se han detectado semillas de lino en niveles del Bronce Medio de Cova Punta Farisa (Fraga), en el enclave griego de Emporion (L'Escala) y en época romana en la villa de $\mathrm{Vi}$ lauba (Camós) (Alonso y Buxó, 1993: Buxó. 1986; Roure et alii., 1988).

Las condiciones actuales, en una zona de transición hacia características continentales. el periodo frío invernal de dos meses y la aridey estival elevada (con sólo $50 \mathrm{~mm}$ de precipitación en los meses de verano) permiten el cultivo del lino de invierno. A pesar de ello las condiciones existentes en el momento de ocupación del poblado serían parcialmente diferentes dado que si tenemos en cuenta los estudios realizados sobre el desplazamiento latitudinal de la vegetación en el litoral mediterráneo a través de los análisis polínicos observaríamos que, a medida que avanza la maquia sobre el encinar, se ha producido un alargamiento del periodo estival seco (Parra, 1993). La reducción de los bosques y la sobreexplotación agrícola ha contribuido a la degradación actual. Los suelos eran mucho más ricos, y la circulación de corrientes de agua mucho mayores que las actuales.

\section{AGRADECIMIENTOS}

Hemos de agradecer especialmente la colaboración de J.E. Zamora del Seminari d'Estudis i Recerques Prehistòriques de la Universidad de Barcelona, S. Ventosa del Museu d'Indústries i Tradicions Populars (Barcelona), R.M. Martín y T. Bastardes del Museu Tèxtil i de la Indumentària (Barcelona) y M.C. Amouretti del Centre Camile Julian (Aix-en-Provence), así como al Servei de Biblioteques i del Patrimoni Bibliogràfic de la Direcció General del Patrimoni de la Generalitat de Catalunya y al Servei de Microscopia Electrònica dels Serveis Científico-Tècnics de la Universitat de Barcelona.

\section{BIBLIOGRAFIA}

Al, N, D , B1 \a, R (1993): "Resultados iniciales del cotuder arqueohotanico de semillas y frutos del yacimiento de (ina Punta Farisa (Fraga. Hucsca)". Estudios de la Annzuedud. o 7 - 4 - Fo Bellaterra.

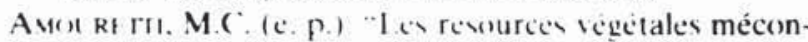
nues de la chóra". En Table ronde: Territoires des cités grecques": Bulletin de Correspondance Hellenique d'Ecole Française d'Athenes. Athenes.

Bixo. R. (1986): "Estudio paleocarpológico". En F. Sanmarti-(irego. P. Castanyer. J. Tremoleda I J. Barhera: "Las estructuras griegas del s.V-VI a.C. halladas en el sector sur de la necrópolis de Ampurias (campaña de excavaciones del año 1986)". (uadernos de Prehistoria 1. Arqueologia Castellonenses, 12: 199-207.

(i ARk. J.G.D. (195.5): “L. Europe' préhistorique. Le's fondements de son économie". Bibliotèque Historique. Payot. Paris.

Esai: K. (1985): “Anatomia vegetal”. Ed. Omega. Barcelona.

Garcia-Calderón. N.E.: Jlian, J.; Pinilla, A. \& Galicia. S. (1992): “Aportación de los análisis fitolitológicos al estudio de un andosol: el Nevado de Toluca o Xinantcatl. Míxico“: Actas del XII Congreso Iberoamericano de la Ciencia del Suelo: 1498-15()6. Salamanca.

Geutr. A. (1979): "A history of textile ari". Pasold Research Foundation Limited in Association with Sotheby Parke Bernet Publications. Londres.

Jt A.s. J. (1993): Análisis de fitolitos en suelos arqueoligi-. cos: El Abric del Filador (Margalef de Montsant, Priorat. Tarragona). Nuevas aportaciones paleoetnobotánicas. Tesis de Licenciatura (inédita). Universitat de Barcelona.

KORBER-GROHNE, V. (1988): "Microscopic methods for identification of plant fibres and animal hairs from the Prince's Tomb of Hochdorf. Southwest Germany" Journal of Archaeological Science, 15: 73-82. Londres.

LAZARKÉvitch. N.A. (1925): "Le lin. Sa culture et son industrie dans l'Europe Occidentale". Gauthier-Villars et Cic. Paris.

Lfon-Garre, A. (1964): "Manual de agricultura". III. Técnica de la producción vegetal e industrias fitógenas: herbocultura. Colección Agrícola Salvat. Ed. Salvat. Barcelona.

Leospo, E; Pedrini, L. y Chiotasso, L. (1989): "Deux tuniques égyptiennes d'Assiout (Haute Égypte) conservés dans le Musée Égyptien de Turin“. En Tissage, Corderie, Vannerie. IX Rencontres Int. d'Archéologie et Histoire d'Antibes (Oct. 1988, Juan-les-Pins): 75-80. Antibes.

Liró Ortiz. L. (1968): "La linaza. Cultivo de lino para grano". En "Diez temas sobre plantas industriales". Ministerio de Agricultura. Madrid: 175-192.

Mille, P.; Colardelle, M. Verdel, E. (1989). "L'artisanat textile au XI siècle Charavines-Colletière (Isére)". En Tissage, Corderie, Vannerie. IX Rencontres Int. d'Archéologie et Histoire d'Antibes (Oct.1988, Juanles-Pins): 249-258. Antibes.

Miró Laporta, V. (1908): "Materias textiles. Primeras lecciones de tecnología textil”. Barcelona. 
PARRA, I. (1993): "Desplaçaments latidudinals de la vegetació al litoral mediterrani durant els darrers 8500 anys. Un enfocament pol.línic i climàtic". Revista Catalana de Geografia, 21: 36-44. Barcelona.

Remussı, C. (1956): "Plantas textiles. Su cultivo e industrialización". Colección Agrícola Salvat. Ed. Salvat. Barcelona.

Renfrew C. \& BAhn P. (1993): "Arqueología. Teorías, métodos y práctica". Akal Ediciones. Madrid.

Roure I Bonaventura, A.; Castanyer I Masoliver, P.; Nolla i Brufau, J.M.; Keay, S.J. i Tarrús I Galter, J.
(1988): La vil.la romana de Vilauba (Camós). Estudi d'un assentament rural (campanyes de 1979-85). Sèrie Monográfica, 8. Centre d'Investigacions Arqueològiques de Girona. Girona.

SCHERY, R.W. (1956): "Plantas útiles al hombre (botánica económica)". Colección Agrícola Salvat. Ed. Salvat. Barcelona.

SERRA, M. (1879): "Elementos de agricultura". Barcelona. $2^{2}$ edición. 